\title{
Technology and Design of Intelligent Casting and The Drying Line for Sanitary Ceramics
}

\author{
Huachao Lv ${ }^{1 *}$, Dianwei Wang ${ }^{1}$, Ying Wang ${ }^{1}$, Qiqi Zhang ${ }^{1}$ \\ ${ }^{1}$ China building materials inspection and Certification Group Shaanxi Co., Ltd. Xi'an 710116, Shaanxi
}

\begin{abstract}
Firstly, the social production demand of sanitary ceramic intelligent manufacturing mold drying line is described. Secondly, the technological process of intelligent manufacturing mould drying for sanitary ceramics was analyzed, and the overall design scheme and implementation method of intelligent manufacturing mould drying line were put forward. Again the key equipment of intelligent manufacturing die drying line is analyzed and explained again, its structural characteristics, functions and characteristics are introduced, and its working principle is explained in detail. Finally, the feasibility and superiority of intelligent mould drying for sanitary ceramics were proved.
\end{abstract}

\section{Introduction}

With the rapid development of society, the high-speed and automation of the whole production process are paid more and more attention by various production enterprises. The automation of sanitary ceramics in China started relatively late. All along, the production of sanitary ceramics is mainly artificial, with high labor intensity, low efficiency, high production cost and low yield, which greatly weakens the competitiveness of the market [1,2]. Therefore, it is of great significance for China's ceramic industry to develop intelligent production line of sanitary ceramics, provide more energy-saving, environmental protection and more efficient intelligent mechanical equipment for ceramic production enterprises, reduce labor intensity, reduce production costs, improve work efficiency, improve productivity, and save energy, which is of great significance to China's ceramic industry, and also bring huge economic benefits to the society. Mold drying line is an important part of sanitary ware intelligent manufacturing production line. Under the operation of mold drying line and bottom mold drying double speed line, automatic and rapid drying can be realized through the hot air pipe in the mold drying room (hot air is the secondary utilization of residual temperature after furnace heating), and the mold is closed directly at the end of the drying room. The whole process improves the efficiency of products, reduces the waste of manpower, material resources and time, and optimizes the working environment of workers.

\section{Analysis of process flow of mould drying room}

\section{1 traditional mold drying process}

At present, there are many kinds and styles of sanitary ceramics in China. But the mold drying is basically the same. The grouting workshop where the workers work is a large drying room. The temperature of the grouting workshop is $36^{\circ} \mathrm{C}$ and the humidity is above $90 \%$. In order to save the cost, the mold is placed very close, the space is narrow and oppressive. After the mold is opened, the blank is turned over manually and the blank body is pulled away. After opening the mold, the mold is placed in the original position and dried by indoor temperature, which needs to be placed for a long time. After being used several times, the mould needs to be removed and transported to a special drying room for drying to a certain extent, and then loaded onto the traditional grouting turnover line.

Due to the inconvenience of mold handling, mold drying needs to be carried out in the grouting workshop. Mold drying needs high temperature and certain wind speed, so it can only be carried out when no one is working, that is, after work at night. This results in a grouting workshop can only open the mold once a day, that is, a set of mold can only produce a set of connected toilet every day.

Generally speaking, the traditional drying process covers a large area, poor working environment, long production cycle, low output and high labor intensity, which requires experienced and tacit cooperation of operators. With the increase of labor cost, the requirement of working environment is higher and higher. I believe that more and more people are not willing to accept this kind of work, especially the young people nowadays. Imagine,

*Corresponding author's e-mail: ctclhc@aliyun.com 
a few years later, the ceramic factory will be able to recruit grouting workers?

\section{2 mold drying process}

In this paper, taking the toilet as an example, the mold drying line is described. This equipment can realize the drying process of the toilet with different overall size, and the drying process of the toilet with different shapes remains unchanged. The process flow of mold drying line is shown in Figure 1.



Fig 1. Drying Process Flow Chart

The selected position of the mold drying line is connected with the mold closing machine so that the mold can be closed directly after drying, which is convenient and efficient. In the mold drying line, all the mold trolleys and bottom mold supporting plates to be dried are transported to the mold drying line. The power mechanism makes the mold trolley and the bottom mold support plate pass through the drying room at a uniform speed, and the mold is dried to a certain extent through the hot air system.

The specific process is as follows:

(1) The mold trolley is transported to the mold opening station, and the latch is opened manually. Then the side mold is opened automatically by the mold opening machine. The bottom mold is extracted and placed on the bottom mold conveying line. The back body mold is manually removed and placed in the specified position of the mold truck.

(2) After the bottom mold is extracted, it is put into the installation position of the bottom mold support plate and transported to the drying room with the empty central line for drying.

(3) The die car is transported to the turnover station, in the process of conveying, the consolidation process is completed. The turnover machine will automatically turn out the green billet and put it on the mold supporting plate. Then the top die of the mold will be returned to the original position. The hanging pieces and internal small parts will be manually taken out and put into the original position of the mold.

(4) After a certain period of time, the mold trolley and the corresponding bottom mold are sent to the mold closing machine at the same time to complete a cycle.
(5) The temperature, humidity and wind speed have been adjusted properly.

(6) With the operation of creeping mechanism and double speed line, when the die trolley and bottom die support plate run to the outlet of drying room, the mold has reached the required drying degree, and the mold can be closed.

\section{Composition of mould drying line.}

The mold drying line consists of four parts: the rigid frame of the mold drying room, the mold drying line, the bottom mold drying line and the drying system.

Composition of the outside of mould drying room.

\section{1 composition of mold drying line.}

The mold drying line is shown in Figure 2.

\section{Mold drying line composition}

Mold drying line is composed of four parts: mold drying frame, mold drying line, bottom mold drying line, and drying system.

\subsection{Mold drying line body composition}

The drying line of the mold is shown in Figure 2. 


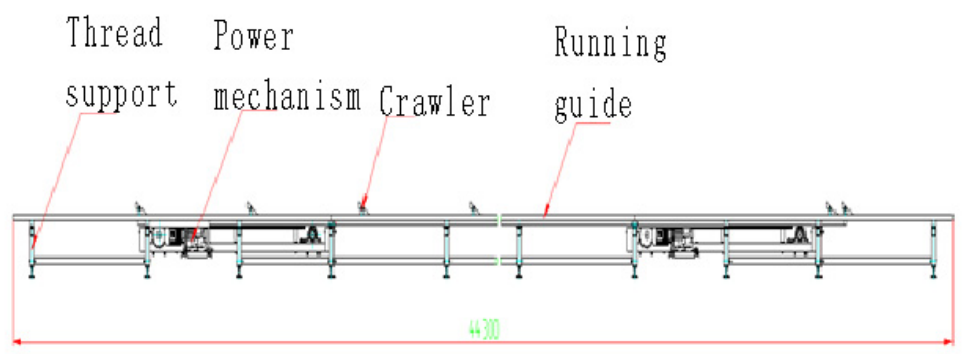

Fig 2. Mold Drying Line

The mold is composed of top mold, side mold, bottom mold, back mold at the position of drain pipe, small parts in water tank and hanging parts in urinal.

The mold drying line is composed of four parts: line support, power mechanism, crawling frame and running guide rail. According to the design production requirements, 600 billets are produced every day. Therefore, there are 3 mold drying lines with a total length of $44.3 \mathrm{~m}$. Each line can store up to 31 mold trolleys for drying. The rail car carries the mold trolley into the designated position of the mold drying line. The power mechanism of the mold drying line is started to drive the crawler to move forward. The hook on the crawling frame hooks the bottom beam of the mold trolley and drives the mold trolley to move forward together. At the same time, the hot air and hot water pipe radiate heat from the hot air pipe to heat and dry the mold, so that the mold car can meet the mold closing requirements when passing through the drying line.

\section{2 composition of bottom mold drying line}

The main structure layout of the bottom mold drying line is shown in Fig. 3.

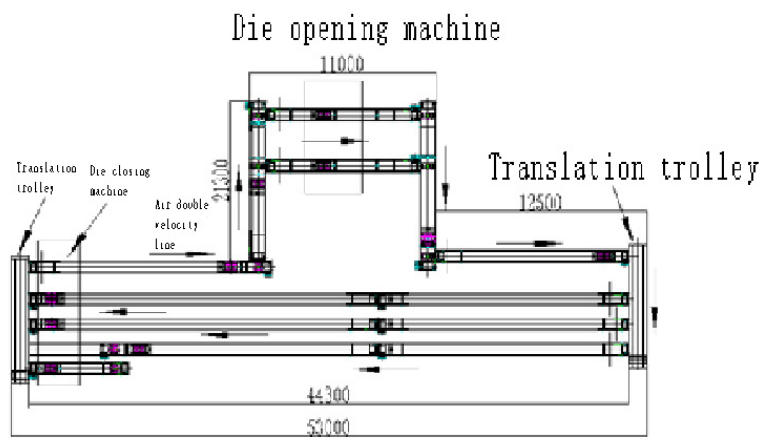

Fig 3. Layout of Bottom Mould Conveyor line

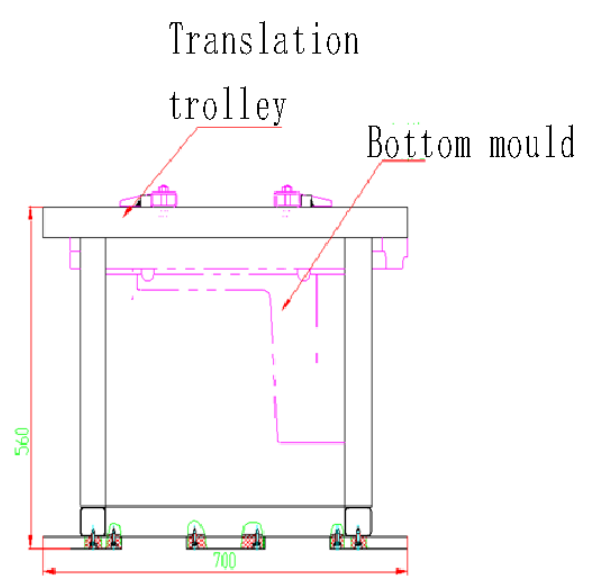

Fig 4. The Mold Bottom Plate

The total length of the bottom mold drying line is $44.3 \mathrm{~m}$, and there are 3 drying double speed lines in total. Each line can store 49 bottom mold supporting plates. The bottom mold drying line is mainly composed of double speed profile, double speed chain, head and tail frame, and motor, so that the double speed chain profile is built on the upper layer of the rigid frame of the mold drying room.

Bottom mold supporting plate: the bottom mold is fixed on the supporting plate and moves along with the bottom mold. There are two rectangular tubes and wedges on the top of the bottom mold to limit each other with the limit block of the bottom mold supporting plate. Take out the bottom mold, and open (shrink) the rectangular tube by opening and closing the bottom mold taking device, so as to place (take out).

Track trolley (located at both ends of grouting creeping line and grouting turnover line): drag the mold trolley at the end of grouting creeping line and grouting turnover line to track trolley, and then transport it to the starting station at the front end of the next grouting creeping line or grouting turnover line.

Mold drying room: high temperature, fast wind speed, quickly, evenly and thoroughly dry the gypsum mold on the mold trolley and bottom mold supporting plate to a certain requirement. Mold opening machine: lift the bottom mold of the mold trolley that reaches the mold opening station and put it into the bottom mold base, and then open the side mold, which can save labor and improve the mold opening efficiency.

Die closing machine: close the side die of the die car arriving at the die closing station, then lift the bottom die 
to the die closing station, put it into the die car, and automatically insert the wedge block. It can save manpower and improve the efficiency of mold closing. Turnover machine: put down the bottom bracket of the mold trolley which reaches the turning position with the mold support plate at the position. The mechanical cooperation is more rigorous and there will be no turbulence. The success rate of turnover is higher and the green billet is not easy to be damaged.

Double speed line in the air: double speed chain line is adopted to make the setting of work station more flexible. The bottom mold can be transported in the air without interference with the ground line, and the space utilization rate can be improved.

Translation car: used for the transfer of the bottom mold support plate between multiple speed lines in a short distance, which can save cost without affecting the beat.

\section{3 composition of drying system}

The drying system is divided into two parts: hot air pipe and hot water pipe. The temperature of the drying room should be controlled at $40{ }^{\circ} \mathrm{C}-50{ }^{\circ} \mathrm{C}$ and the humidity should be controlled at $60 \%-70 \%$. The specific situation depends on the weather, environment and temperature of the workshop at that time. There are 2 hot air pipes in total. The hot air pipes are $35 \mathrm{~m}$ long and $500 \mathrm{~mm}$ in diameter. Each hot air pipe is provided with several small holes with a diameter of $50 \mathrm{~mm}$. According to the specific situation, determine the position of the small hole to ensure that both sides of the mold can be blown. The hot water pipe is mainly in the heat dissipation position, which is surrounded by the steel structure of the drying room. Hot air pipe and hot water pipe are the secondary utilization of waste heat after furnace heating. After heat dissipation through drying room, hot water pipe flows into furnace heating water again to circulate.

\section{Conclusion}

Mold drying line replaces the traditional drying method, improves the working environment of workers and greatly reduces the labor force. The time of drying process can be well controlled, the requirements for workers' experience are reduced, the mold drying is basically separated from manual work, and the heavy physical labor of workers is also perfectly removed. Mold drying is also faster and more thorough, improve the mold utilization rate and pass rate, so as to improve the output, improve the income of enterprises and companies. At the same time, it can meet the production requirements of different types of connected toilet, which is suitable for the production and development requirements of enterprises, and has a broad development prospect. It has certain reference value and guiding significance for the design and development of other types of sanitary ceramic production line [16].

\section{Acknowledgments}

This work was supported by the study was supported by Public Service Platform Project of Industrial Technology
Foundation of Ministry of Industry and Information Technology in 2020 (No.2020-0098-2-1)

\section{Reference}

1. Xu Xiwu. Five year retrospective analysis on the output and quality of China's building and sanitary ceramics industry $[\mathrm{J}]$. China ceramic industry, 2015,22 (01): 22-26

2. Zeng Jie, Yu Haiyong, Yan Weiguo, Zhang He. Carbon footprint of building and sanitary ceramics based on life cycle theory [J]. Silicate bulletin, 2014,33 (01): 54-58 + 62

3. Wang Rongjie, Du Xiafang. Development status and future development trend of building and sanitary ceramics industry in China [J]. Ceramics, 2013 (06): 9-12

4. Bai Zhanying, Zhang Weixing, Liu Xiaoyun. Technical status and development trend of building and sanitary ceramics industry in China [J]. Ceramics, 2011 (12): 40-43

5. $\mathrm{Li}$ zewen. Development status and Prospect of domestic ceramic industry $[\mathrm{J}]$. Foshan ceramics, 2011,21 (09): 6-11

6. Nie Baomin. Development and direction of China's sanitary ceramics industry [J]. Ceramics, 2011 (04): $21-24$

7. Li Jiyuan, Ma Yushu. Comprehensive experimental design of ceramic grouting molding $[\mathrm{J}]$. Science and technology innovation guide, 2013 (09): $247+249$

8. Deng Zhuming, Gou Li, ran Junguo. Rheological properties of Yb: YAG laser ceramic slurry prepared by grouting [J]. Silicate bulletin, 2013,32 (02): 221$224+230$

9. Li Jia. Study on the performance of plaster mold for sanitary ceramics by grouting [D]. South China University of technology, 2012

10. Wu Xie, Chen Zhenhua, Li Fuying. Preparation of alumina ceramic elbow by grouting method $[\mathrm{J}]$. China ceramics, 2011,47 (08): 50-53

11. Deng Shichao. Research on digital design and manufacturing technology of toilet products [D]. Hunan University, 2011

12. Zhou Jun, pan yubai, Li Jiang, Zhang Wenxin, Kou Huamin, Liu Wenbin, Guo Jingkun. Preparation of YAG Transparent Ceramics by grouting with anhydrous ethanol [J]. Acta inorganic materials, 2011,26 (03): 254-256

13. Wang Xingang, Liu Jixuan, Jian Yanmei, Zhang Guojun, Wang Peiling, ZrB_ Injection molding and pressureless sintering of $2-\mathrm{SiC}$ ceramics $[\mathrm{J}]$. Acta inorganic materials, 2009,24 (04): 831-835

14. Hao Hongshun, $\mathrm{Xu}$ Lihua, Zhen Xiaomeng, Yang Jianying, Liu Ming, Yin hang. Preparation of high wear-resistant alumina ceramics by slip casting process [J]. Acta silicate Sinica, 2008 (11): 1615-1619

15. Wang Wenli, Kang Yongfeng. The important role of 
process in the design and operation control of intelligent manufacturing production line [J]. Aviation manufacturing technology, 2016 (16): 48-51 $+62$

16. Shan Jidong, Wang Zhaoyang, Chen Heli, Cao Zengyi. Research on the construction technology of aeroengine intelligent manufacturing production line [J]. Aviation manufacturing technology, 2016 (16): $52-56$

17. Zhang Shumei, Yang Genjun, Chen Jun. research and application of intelligent manufacturing technology for aircraft assembly pulse production line [J]. Aviation manufacturing technology, 2016 (16): 41-47

18. Gao Zhiquan. Dongguan strives to build more than 100 universal intelligent manufacturing production lines [n]. Dongguan daily, July 23, 2016 (A02)

19. Bai Ruifeng, Han Honghong, Yu Heyang, Fang Zhaohui. Design and integration of virtual experimental system for intelligent manufacturing [J]. Experimental technology and management, 2016,33 (06): $129-131+149$

20. Shan Shengyu, Chen Xubing, Wang Yuhui, Zhang Chao. Research on the reading and writing performance of UHF RFID reader for intelligent manufacturing production line $[\mathrm{J}]$. Modern electronic technology, 2013,36 (11): 131-133 